\title{
Active Thermography in Qualitative Evaluation of Protective Materials
}

\author{
Grzegorz Gralewicz \\ Department of Personal Protective Equipment, Central Institute for Labour Protection - \\ National Research Institute (CIOP-PIB), tódź, Poland
}

\section{Bogusław Więcek}

Institute of Electronics, Technical University of Łódź, Łódź, Poland

This is a study of the possibilities of a qualitative evaluation of protective materials with active thermography. It presents a simulation of a periodic excitation of a multilayer composite material. Tests were conducted with lock-in thermography on Kevlar ${ }^{\circledR}$ composite consisting of 16 layers of Kevlar ${ }^{\circledR}$ fabric reinforced with formaldehyde resin with implanted delamination defects. Lock-in thermography is a versatile tool for nondestructive evaluation. It is a fast, remote and nondestructive procedure. Hence, it was used to detect delaminations in the composite structure of materials used in the production of components designed for personal protection. This method directly contributes to an improvement in safety.

protective material active thermography defects

\section{INTRODUCTION}

The structure of materials used in the production of components designed for personal protection, e.g., multilayer composites, is heterogeneous and anisotropic. By selecting proper ingredients, it is possible to obtain materials with higher impact strength or enhanced energy absorption. The properties of protective materials change whenever the structure of the material features lamination, air bubbles, fractures, etc., during the technological process or later.

The qualitative evaluation of a protective material consists in identifying defects present in the material. To this aim, active thermography technology has been employed. It is a nondestructive evaluation method $[1,2,3,4,5,6]$, in which tested items are excited with input energy, while an infrared camera measures the changes in temperature distribution in time. Heat spreads in solid materials through diffusion, which strongly depends on the thermal qualities of the material.

\section{THEORY}

In order for inserts and material discontinuities to be detected with active thermography, the relations of time and space in temperature distribution following energy input must be described, providing for relevant features of the tested material (thermal conductivity $k$, specific heat $c_{w}$, density $\rho$ ). In active lock-in thermography $[7,8]$ the energy input and the thermal response to that input are periodic and synchronic. When dealing with periodic temperature fluctuations it is convenient to focus on temperature excess $\Delta T$ above the average material surface temperature $T_{p}$. When looking at the first-type boundary condition, each periodic temperature change $T_{0}$ and its excess

Correspondence and requests for offprints should be sent to Grzegorz Gralewicz, Central Institute for Labour Protection - National Research Institute, ul. Wierzbowa 48, 90-133 Łódź, Poland. E-mail: <grgra@ ciop.pl>. 
$\Delta T_{0}$ in the surface of the material $(x=0)$ can be represented as a Fourier series (solid angle $\omega$, time $t$ ):

$$
\begin{aligned}
& \Delta T_{0}=T_{0}-T_{p}=\sum_{i=1}^{n}\left(A_{i} \cos k \omega t+B_{i} \sin k \omega t\right) \\
& =\sum_{i=1}^{n} C_{i} \sin \left(k \omega t+\varphi_{i}\right),
\end{aligned}
$$

where

$$
C_{i}=\sqrt{A_{i}^{2}+B_{i}^{2}}, \quad \operatorname{tg} \varphi_{i}=\frac{A_{i}}{B_{i}} .
$$

When looking only at one harmonic with its maximum temperature amplitude $\Delta T_{A 0}$ in the surface of the material $(x=0)$

$$
\Delta T_{A 0}(t)=T_{0 m} \cos \omega t,
$$

we come up with the following equation describing temperature fluctuation within the half-finished material [9]:

$\Delta T(x, t)=\Delta T_{A 0} \exp \left(-\sqrt{\frac{\omega}{2 a}} x\right) \cos \left(\omega t-\sqrt{\frac{\omega}{2 a}} x\right)$,

where

$$
a=\frac{\rho c_{w}}{k},
$$

$\rho$-density $\left(\mathrm{kg} \cdot \mathrm{m}^{-3}\right), c_{w}$-specific heat $\left(\mathrm{J} \cdot \mathrm{kg}^{-1} \cdot \mathrm{K}^{-1}\right)$, $k$-thermal conductivity $\left(\mathrm{W} \cdot \mathrm{m}^{-1} \cdot \mathrm{K}^{-1}\right)$.

The temperature fluctuates in line with the cosine function with suitably reduced amplitude and phase shift. The temperature fluctuation amplitude $\Delta T_{A x}$ at $x$ distance from the halfinfinite material surface is identified with Equation 4, when

$$
\cos \left(\omega t-\sqrt{\frac{\omega}{2 a}} x\right)=1 \text {. }
$$

Therefore, the further away from the surface of the material we move, the ratio of the amplitude at $x$ depth to the amplitude on the surface of the body $(x=0)$ will decrease exponentially as in Equation 7:

$$
\frac{\Delta T_{A x}}{\Delta T_{A 0}}=\exp \left(-\sqrt{\frac{\omega}{2 a}} x\right) .
$$

Penetration depth of the heat wave can be represented as the distance at which the wave amplitude is reduced to 0.01 of the amplitude on the surface of the body [9], and therefore

$$
x=\sqrt{\frac{2 a}{\omega}} \ln \frac{\Delta T_{A 0}}{\Delta T_{A x}} .
$$

According to Equation 3 the average value of temperature excess $\Delta T_{A 0}$ on the surface of the material is achieved in the time $t_{A 0}$ when $\cos \omega t_{A 0}=0$,

$$
t_{A 0}=\frac{\pi}{2 \omega} \text {. }
$$

The same average temperature excess $\Delta T_{A 0}=0$ is reached at $x$ depth under the surface, as in Equation 4 in the time $t_{A x}$ when $\cos \left(\omega t_{A x}-\sqrt{\frac{\omega}{2 a}} x\right)=0$,

$$
t_{A x}=\frac{\pi}{2 \omega}+\sqrt{\frac{1}{2 a \omega}} x .
$$

The lag of the heat wave in the material is

$$
\Delta t_{A}=t_{A x}-t_{A 0}=\sqrt{\frac{1}{2 a \omega}} x .
$$

The length of the heat wave corresponds to the span between times $t=0$ and $t=t_{1}$ : $\cos \left(\omega t-\sqrt{\frac{\omega}{2 a}} x\right)=1, \omega t-\sqrt{\frac{\omega}{2 a}} x=0$, where $t=0$ results in $x=0$, and $t=t_{1}$ results in

$$
x=\frac{\omega t_{1}}{\sqrt{\frac{\omega}{2 a}}}=2 \sqrt{\pi a t_{1}} .
$$

Equation 12 shows that being independent from $x$, the length of the heat wave does not change as it penetrates deeper into the structure of the material.

The heat stream density for temperature fluctuations can be calculated with Fourier's law $\frac{\partial T}{\partial t}=\frac{k}{\rho c_{w}} \frac{\partial^{2} T}{\partial x^{2}}$. The temperature gradient is calculated by differentiating Equation 4:

$$
\begin{aligned}
& \frac{\partial \Delta T}{\partial x}=-\Delta T_{A 0} \sqrt{\frac{\omega}{2 a}} \exp \left(-\sqrt{\frac{\omega}{2 a}} x\right) \\
& {\left[\cos \left(\omega t-\sqrt{\frac{\omega}{2 a}} x\right)-\sin \left(\omega t-\sqrt{\frac{\omega}{2 a}} x\right)\right] .}
\end{aligned}
$$

Therefore,

$$
\begin{aligned}
& q_{x}=k \Delta T_{A 0} \sqrt{\frac{\omega}{2 a}} \exp \left(-\sqrt{\frac{\omega}{2 a}} x\right) \\
& {\left[\cos \left(\omega t-\sqrt{\frac{\omega}{2 a}} x\right)-\sin \left(\omega t-\sqrt{\frac{\omega}{2 a}} x\right)\right],}
\end{aligned}
$$


for $x=0$, on the surface:

$q_{0}=k \Delta T_{A 0} \sqrt{\frac{\omega}{2 a}}(\cos \omega t-\sin \omega t)$

$=k \Delta T_{A 0} \sqrt{\frac{\omega}{a}} \cos \left(\omega t+\frac{\pi}{4}\right)=q_{\max 0} \cos \left(\omega t+\frac{\pi}{4}\right)$,

where $q_{\max 0}$-maximum heat stream density on the surface:

$$
q_{\max 0}=k \Delta T_{A 0} \sqrt{\frac{\omega}{a}}=\Delta T_{A 0} \sqrt{k \rho c_{w} \omega} .
$$

Penetration depth is reduced along with the rise in the frequency of the heat wave. It also depends on the parameters of the material $(k, \rho$, $\left.c_{w}\right)$. Therefore, knowing at least the approximate value of how thick the layers of the material it is possible to match the energy input impulse duration and/or the frequency of energy input.

The multilayer structure of the composite material was numerically modeled with the finite element method (numerical simulation package ANSYS $^{\circledR}$ release 11.0 UP20070125). ANSYS $^{\circledR}$ makes dynamic thermal simulations possible, including those for the most frequently experienced boundary conditions (convection, heat stream, radiation, etc.).

Data obtained from ANSYS ${ }^{\circledR}$ was processed with Matlab ${ }^{\circledR}$ version R2008b. The software displays the results visually and makes it possible to calculate the relative difference between the values where the defect is located and its neighboring (defect-free) area. The software was developed to identify the difference between the values of temperature/phase in the location of the defect and in the defect-free area. The marked point defined the temperature of the insert $\left(T_{c}\right)$. The temperature values characterizing the neighborhood were measured in four marked points $\left(T_{1}, T_{2}, T_{3}, T_{4}\right)$. Next, parameters $K T$ and $K \varphi$ were identified; they characterized the difference in the temperature values between the defect-free area and the defect. It was defined as a module of the difference between the value in the central point $T_{c}$ and in the neighboring points $T_{i}$, $i=1-4$, referred to the average values of modules $T_{c}$ and $T_{i}$ :

$$
\begin{aligned}
& K T=\frac{1}{4} \sum_{i=1}^{4} \frac{\left|T_{c}-T_{i}\right|}{\left|T_{c}\right|+\left|T_{i}\right|} \\
& K \varphi=\frac{1}{4} \sum_{i=1}^{4} \frac{\left|\varphi_{c}-\varphi_{i}\right|}{\left|\varphi_{c}\right|+\left|\varphi_{i}\right|}
\end{aligned} .
$$

Figure 1 is a temperature map with the locations of points $T_{c}$ and $T_{i}$ that were used to determine $K T$.

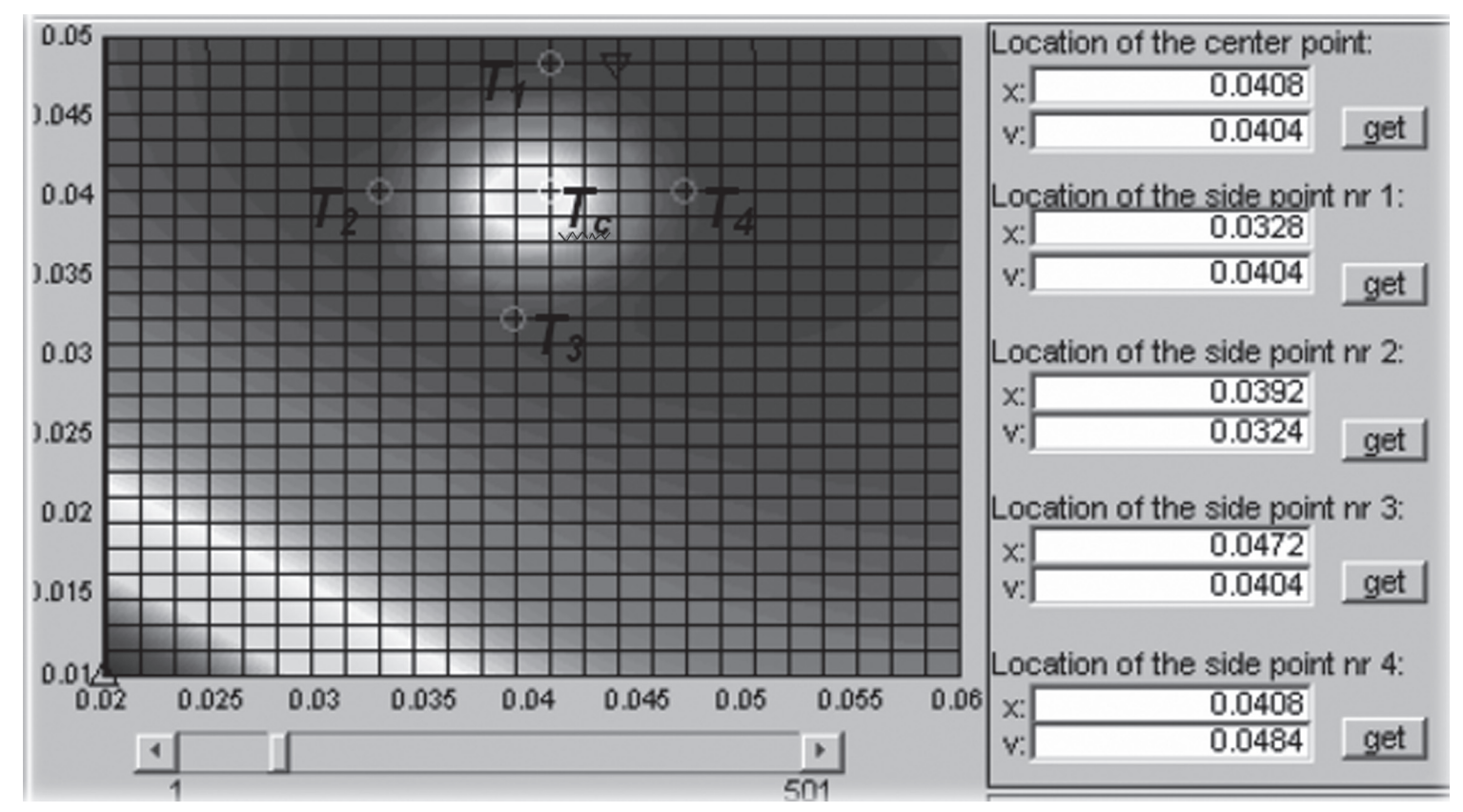

Figure 1. Locations of defect points $T_{c}$ and defect-free points $T_{i}$ used in successive analyses to determine the $K T$ parameter. Notes. $K T$-the difference in the temperature values between the defect-free area and the defect. 
Next, average temperature difference was identified between the defect point $T_{c}$ and the defect-free points $T_{i}$ :

$$
\Delta T=\frac{1}{4} \sum_{i=1}^{4}\left|T_{c}-T_{i}\right| .
$$

The last stage was the lock-in analysis, which identified the difference in the amplitude and the phase between sinusoidal input signal and system response. The parameters analyzed were the frequency $f_{0}$ and the phase $\varphi_{0}$ of the input signal. The values of the amplitude $A$ and the phase $\varphi$ of the response signal were calculated with the following equations [10]:

$$
\begin{aligned}
& A=\frac{2}{N} \sqrt{S Q^{2}+S P^{2}}, \operatorname{tg}\left(\varphi-\varphi_{0}\right)=\frac{S Q}{S P}, \\
& S P=\sum_{i=1}^{N} s\left(t_{i}\right) p\left(t_{i}\right), \quad S Q=\sum_{i=1}^{N} s\left(t_{i}\right) q\left(t_{i}\right), \\
& p(t)=\sin \left(2 \pi f_{0} t+\varphi_{0}\right), q(t)=\cos \left(2 \pi f_{0} t+\varphi_{0}\right),
\end{aligned}
$$

where $A$-amplitude, $\varphi$-phase, $N$-number of recorded images, $t_{i}$-image recording times, $p(t)$-reference signal with phase matching that of input signal, $q(t)$ —signal shifted by $90^{\circ}$ against the input.

The ANSYS $^{\circledR}$ and Matlab $^{\circledR}$ computer simulations were analyzed to identify the frequency range for the energy input which makes detecting defects (material discontinuities) possible.

(a)

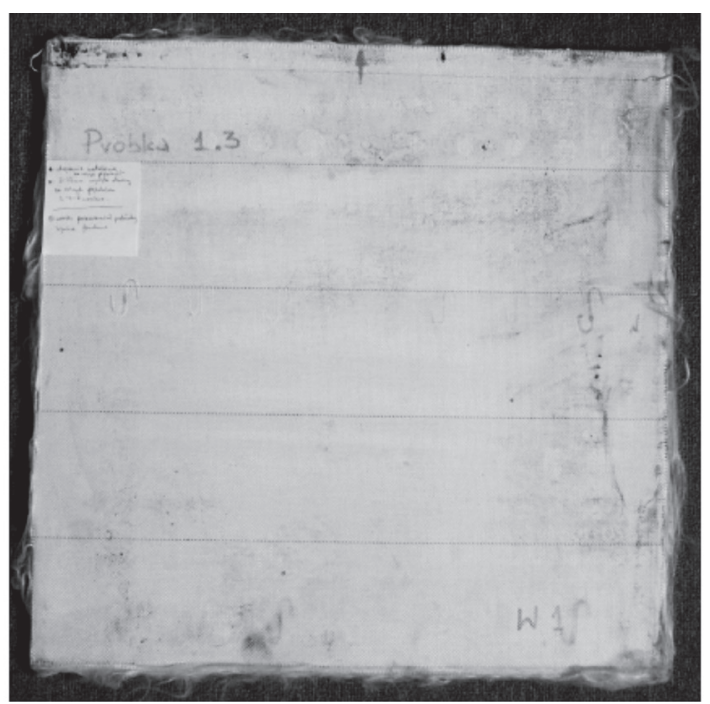

(b)

\begin{tabular}{|ccccc|}
\hline layers 5-6 & layers 4-5 & layers 3-4 & layers 2-3 \\
\hline & $\bigcirc$ & $\bigcirc$ & $\bigcirc$ & $22.0 \mathrm{~mm}$ \\
$\bigcirc$ & $\bigcirc$ & $\bigcirc$ & $\bigcirc$ & $19.0 \mathrm{~mm}$ \\
$\bigcirc$ & $\bigcirc$ & $\bigcirc$ & $\bigcirc$ & $15.8 \mathrm{~mm}$ \\
$\bigcirc$ & $\bigcirc$ & $\bigcirc$ & $\bigcirc$ & $12.7 \mathrm{~mm}$ \\
$\bigcirc$ & $\bigcirc$ & $\bigcirc$ & $\bigcirc$ & $11.1 \mathrm{~mm}$ \\
$\bigcirc$ & $\bigcirc$ & $\bigcirc$ & $\bigcirc$ & $8.0 \mathrm{~mm}$ \\
$\bigcirc$ & $\bigcirc$ & $\bigcirc$ & $\bigcirc$ & $6.4 \mathrm{~mm}$ \\
$\bigcirc$ & $\bigcirc$ & $\bigcirc$ & $\bigcirc$ & $5.6 \mathrm{~mm}$ \\
$\bigcirc$ & $\bigcirc$ & $\bigcirc$ & $\bigcirc$ & $4.8 \mathrm{~mm}$ \\
$\bigcirc$ & $\bigcirc$ & $\bigcirc$ & $\bigcirc$ & $4.0 \mathrm{~mm}$ \\
$\bigcirc$ & $\bigcirc$ & $\bigcirc$ & $\bigcirc$ & $3.2 \mathrm{~mm}$ \\
$\bigcirc$ & $\bigcirc$ & $\bigcirc$ & $\bigcirc$ & $2.0 \mathrm{~mm}$ \\
\hline
\end{tabular}

Figure 2. Composite material: (a) sample and (b) structure with locations of defects of different diameters. 
Energy input of heat stream $\left(\mathrm{W} \cdot \mathrm{m}^{-1}\right): Q(t)$ $=Q_{0}(1+\sin (2 \pi f t))$. Ambient temperature: $T_{\text {room }}=298 \mathrm{~K}$. Convection ratio at the front and back surfaces: front and back: $\alpha_{\mathrm{fb}}=10 \mathrm{~W} \cdot \mathrm{m}^{-2} \cdot \mathrm{K}^{-1}$; sides: $\alpha_{\mathrm{s}}=5 \mathrm{~W} \cdot \mathrm{m}^{-2} \cdot \mathrm{K}^{-1}$.

\section{COMPUTER ANALYSIS RESULTS}

The aim of the computer analysis was to identify the frequency of an input signal that would enable detecting a defect whose parameters (location, size, parameters of the material) were known. The computer model of the structure of the material was developed so that a number of computer simulations could be made for the selected frequency range of energy input source

(a)

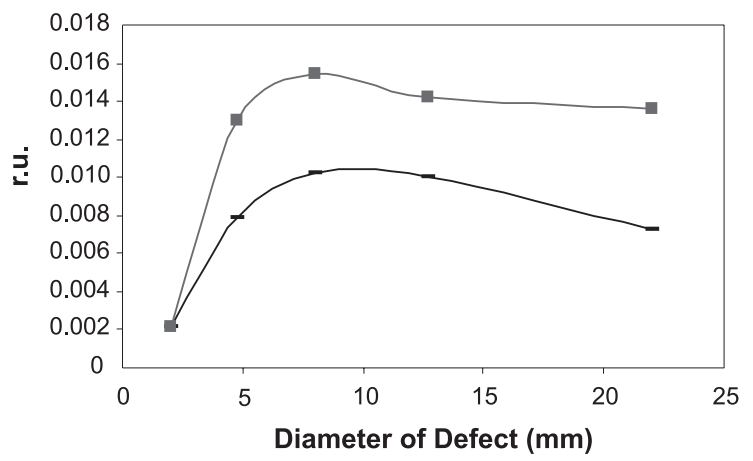

(c)

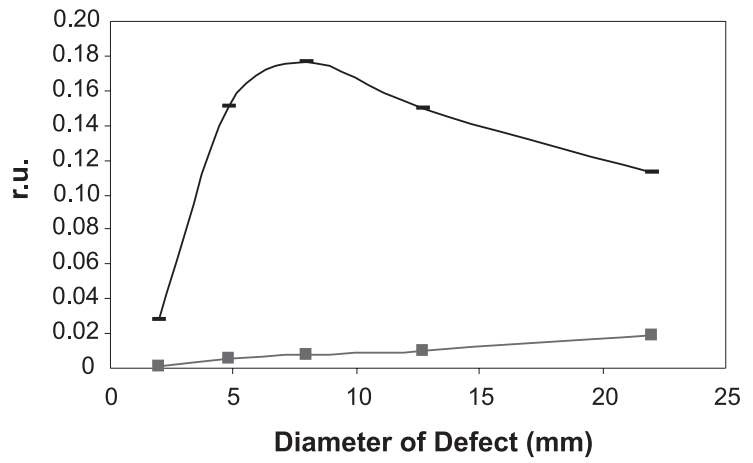

$-K T-K_{\varphi}$
$(0.001-0.100 \mathrm{~Hz})$, the diameter of the defect of $22-2 \mathrm{~mm}$ and for the defect located in layers $2-3,3-4,4-5$ and $5-6$ from the surface. The first simulation package showed the diameter of the defect $(8 \mathrm{~mm})$ for which $K T$ and $K \varphi$ obtained maximum values for a given frequency range (Figure 3).

Another package of computer simulations was prepared for that diameter during which the impact of the frequency of energy input was analyzed. The results of computer simulations indicated the frequency range of $f=0.05-0.07 \mathrm{~Hz}$ with a clear dominance of $0.06 \mathrm{~Hz}$ for which $K T$ and $K \varphi$ obtained the maximum value for all four depths at which the defects were located (Figure 4).

(b)

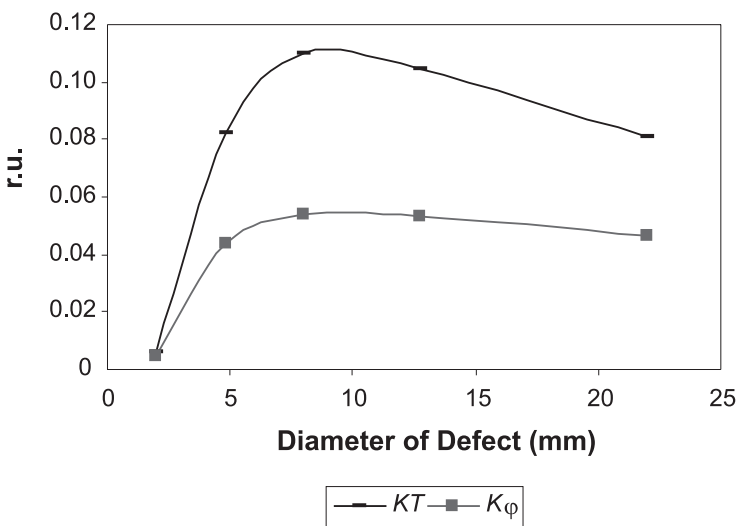

(d)

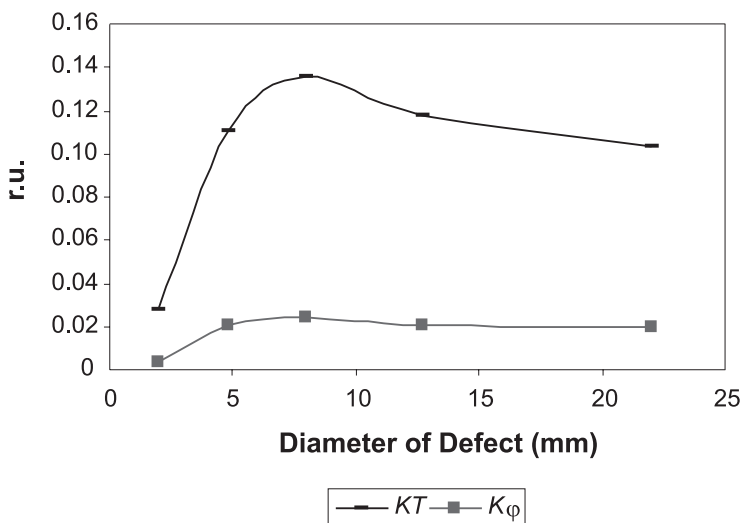

Figure 3. Dependence of parameters $K T$ and $K \varphi$ on the diameter of the defect for frequencies (a) $0.100 \mathrm{~Hz}$, (b) $0.010 \mathrm{~Hz}$, (c) $0.001 \mathrm{~Hz}$ and (d) $0.060 \mathrm{~Hz}$; defect located in layers 2-3. Notes. $K T, K \varphi$-the difference in the temperature/phase values between the defect-free area and the defect. 
(a)

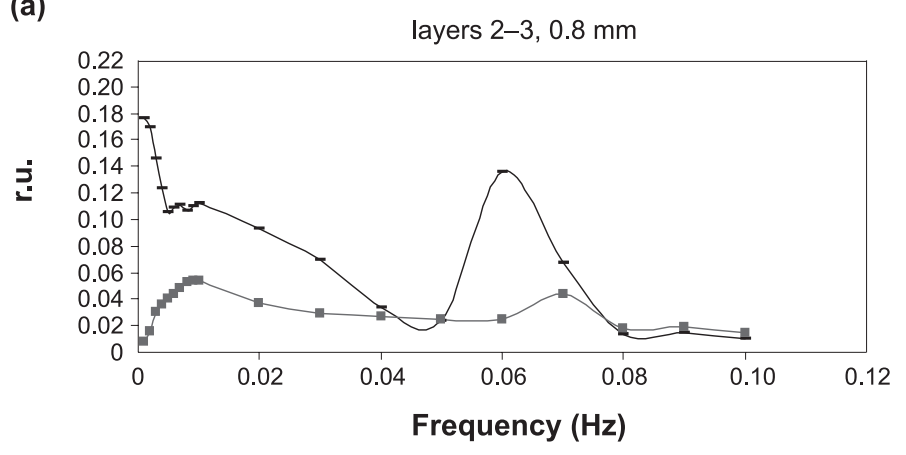

$-K T-K_{\varphi}$

(b)

layers 3-4, $1.2 \mathrm{~mm}$

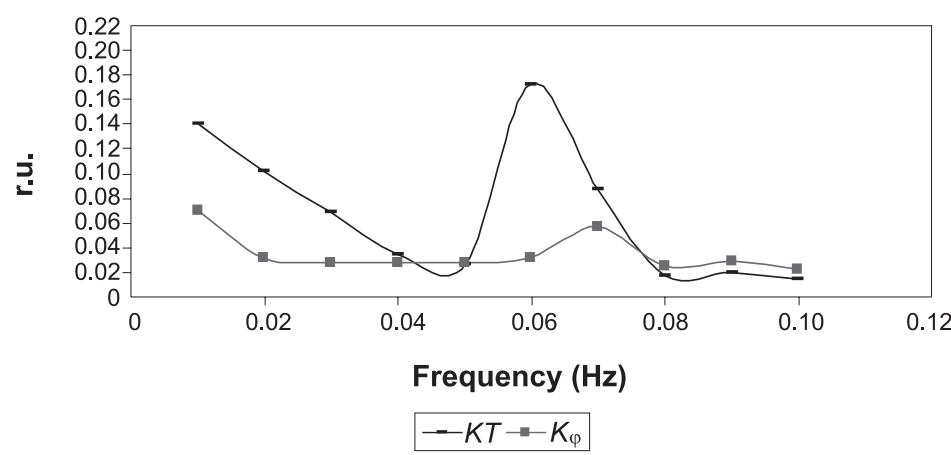

(c)

layers $4-5,1.6 \mathrm{~mm}$

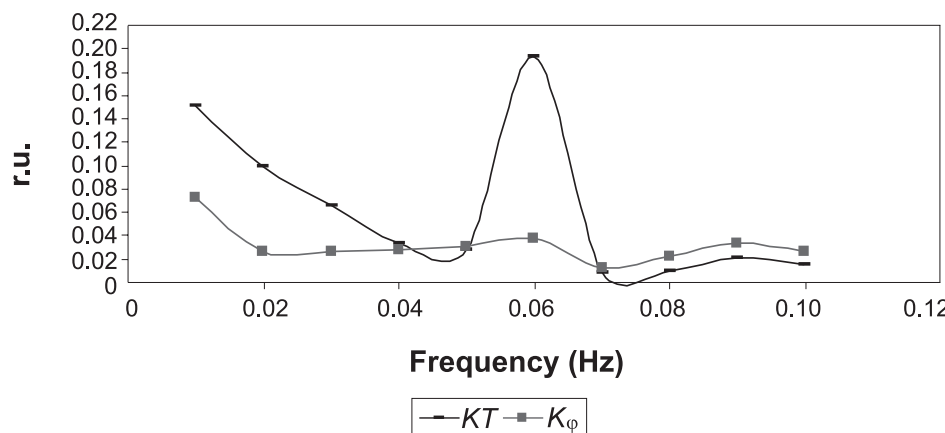

(d)

layers 5-6, $2.0 \mathrm{~mm}$

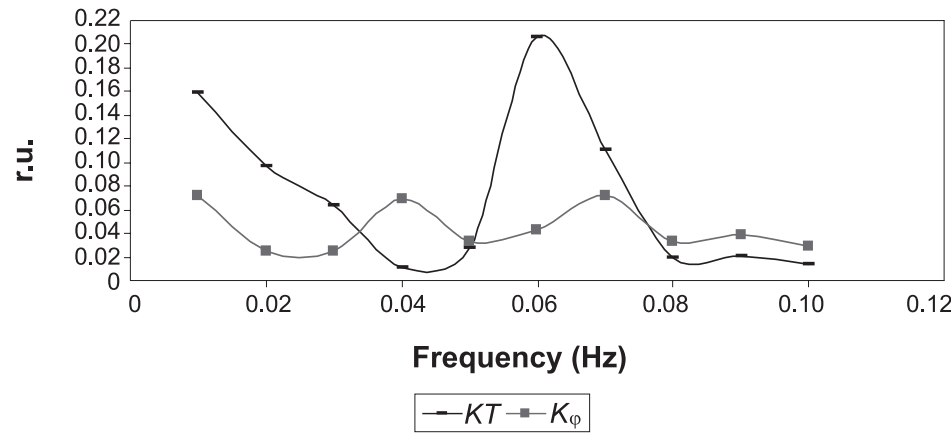

Figure 4. Dependence of parameters $K T$ and $K \varphi$ on the frequency of energy input per 4 depths at which the defects are located; diameter of the defect: $8 \mathrm{~mm}$. Notes. $K T, K \varphi$-the difference in the temperature/ phase values between the defect-free area and the defect. 


\section{CONCLUSIONS FROM COMPUTER MODELING}

The computer simulation package made it possible to choose the frequency of the energy input. To identify the optimum frequency it was suggested that $K T$ and $K \varphi$ for the fringe phase corresponding to the frequency of the source of the energy input should be used; their maximum value indicated the optimum frequency. $K T$ and $K \varphi$ reached their maximum values for $f=$ 0.05-0.07 Hz. Experimental tests of composite materials with inserted defects were carried out for those frequencies.

\section{EXPERIMENTAL TESTS}

The composite material was tested with the thermographic method to verify the frequency of the input signal that was identified during the computer analysis $(f=0.05-0.07 \mathrm{~Hz})$ and for which defects were detectable. A testing sample was prepared; fragments of layers $2-3,3-4,4-5$ and $5-6(22-2 \mathrm{~mm}$ in diameter) were removed (Figure 2).

A measuring system for registering temperature changes in a test object after real-time energy coercion was used. The test stand consisted of a ThermaCam (FLIR Systems, USA) PM290 infrared camera and a computer with software; a lamp system was the source of excitation energy (Figure 5).

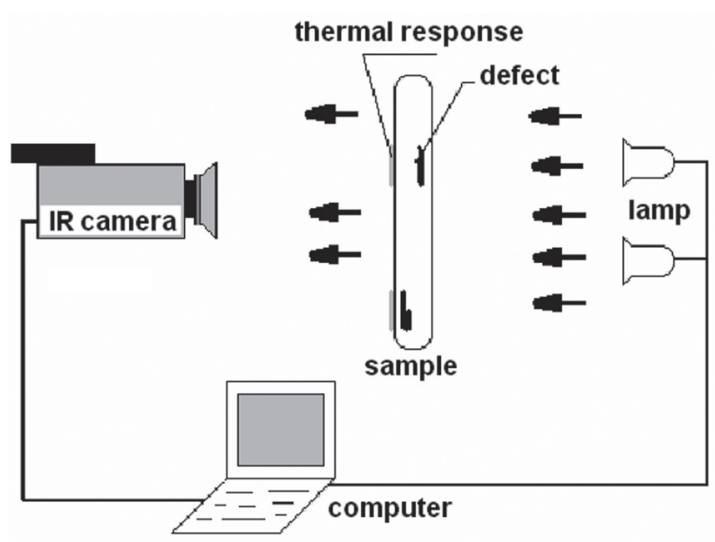

Figure 5. Test stand for nondestructive testing with active thermography. Notes. IR-infrared.
Parameters of the test stand:

- excitation: impulse and periodic;

- generated waves: 500-1700 nm;

- power of the energy input system: $1400 \mathrm{~W}$;

- ThermaCam PM290: IFOV (instantaneous field of view) $16^{\circ}$ lens, $f / 1.5-1.2 \mathrm{mrad}$;

- spectral range of infrared image analysis: 3-5 $\mu \mathrm{m}$;

- resolution of infrared image analysis: $0.1 \mathrm{~K}$.

A sample of the composite material was fixed in a special holder. The infrared camera was focused on the back of the tested material. The ambient temperature was $298 \mathrm{~K}$. The energy input system was placed $50 \mathrm{~cm}$ from the sample, while the sample was placed $3 \mathrm{~m}$ from the infrared camera.

Figure 6 illustrates a sample of the material along with sample amplitude and phase diagrams for $f=0.05 \mathrm{~Hz}$, with marked defects.

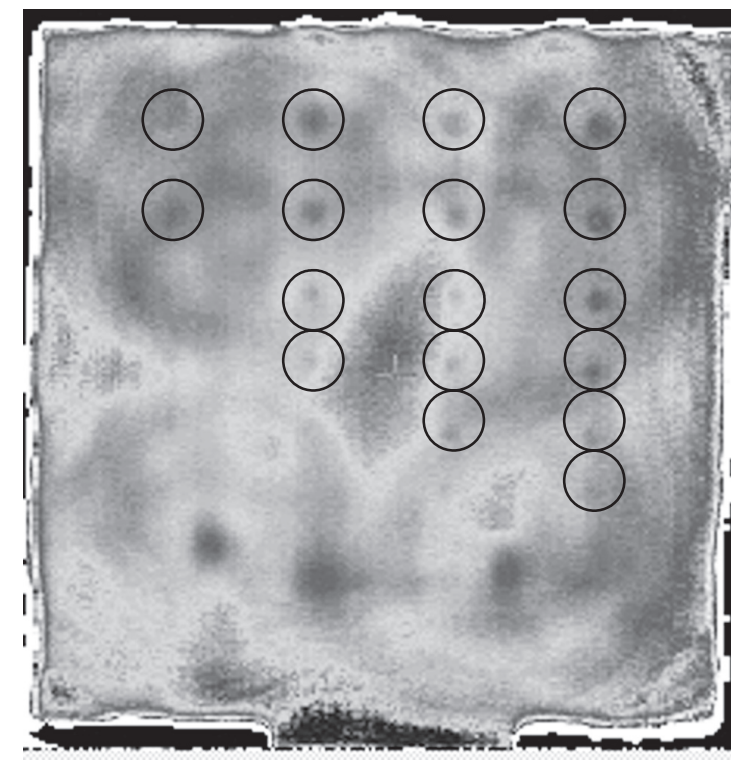

Figure 6. Images of a phase with marked defects. Notes. -location of the defect.

Table 2 lists the results of thermographic tests specifying the frequencies of energy input that made detecting defects possible. The results are for detected defects, other defects were undetectable. 
TABLE 2. Results of Thermographic Tests

\begin{tabular}{|c|c|c|c|c|c|c|c|c|c|c|}
\hline \multirow[b]{2}{*}{ Diameter (mm) } & \multicolumn{10}{|c|}{ Frequency $(\mathrm{Hz})$} \\
\hline & 0.01 & 0.02 & 0.03 & 0.04 & 0.05 & 0.06 & 0.07 & 0.08 & 0.09 & 0.10 \\
\hline \multicolumn{11}{|c|}{ Defects located in layers $2-3$} \\
\hline 22.0 & $x$ & $x$ & $x$ & $\times$ & $x$ & $x$ & $\times$ & $\times$ & $\times$ & $x$ \\
\hline 19.0 & $\times$ & $x$ & $x$ & $x$ & $x$ & $\times$ & $\times$ & $\times$ & $\times$ & $x$ \\
\hline 15.8 & $\times$ & $\times$ & $\times$ & $x$ & $x$ & $\times$ & $\times$ & $\times$ & $\times$ & $\times$ \\
\hline 12.7 & $x$ & $x$ & $\times$ & $\times$ & $\times$ & $\times$ & $\times$ & $\times$ & $\times$ & $\times$ \\
\hline 11.1 & & & $x$ & $x$ & $x$ & $\times$ & $x$ & $\times$ & & \\
\hline 8.0 & & & & & $x$ & & & & & \\
\hline \multicolumn{11}{|c|}{ Defects located in layers 3-4 } \\
\hline 22.0 & & $x$ & $x$ & $\times$ & $\times$ & $\times$ & $\times$ & $\times$ & & \\
\hline 19.0 & & $\times$ & $x$ & $\times$ & $\times$ & $\times$ & $\times$ & $\times$ & & \\
\hline 15.8 & & $\times$ & $\times$ & $\times$ & $x$ & $x$ & $\times$ & & & $x$ \\
\hline 12.7 & & $x$ & $x$ & $x$ & $x$ & $\times$ & $\times$ & & & $x$ \\
\hline 11.1 & & $x$ & $\times$ & $x$ & $\times$ & $\times$ & $x$ & & & \\
\hline \multicolumn{11}{|c|}{ Defects located in layers 4-5 } \\
\hline 22.0 & & $x$ & $\times$ & $x$ & $x$ & $\times$ & $x$ & $\times$ & & \\
\hline 19.0 & & $x$ & $x$ & $x$ & $x$ & $\times$ & $\times$ & & & \\
\hline 15.8 & & $x$ & $\times$ & $\times$ & $\times$ & $\times$ & $\times$ & & & \\
\hline 12.7 & & $\times$ & $\times$ & $\times$ & $\times$ & $\times$ & & & & \\
\hline 11.1 & & & & $\times$ & & & & & & \\
\hline \multicolumn{11}{|c|}{ Defects located in layers 5-6 } \\
\hline 22.0 & & & & $\times$ & $x$ & & & & & \\
\hline 19.0 & & & & & $\times$ & & & & & \\
\hline
\end{tabular}

Notes. $\times$-defects.

\section{CONCLUSIONS FROM EXPERIMENTAL TESTS}

- Defects 22.0, 19.0, 15.8, 12.7, 11.1 and $8 \mathrm{~mm}$ in diameter, located in layers $2-3$, were detected with the frequency of energy input $f=$ $0.05 \mathrm{~Hz}$.

- Defects 22.0, 19.0, 15.8, 12.7 and $11.1 \mathrm{~mm}$ in diameter, located in layers 3-4 were detected with the frequency of energy input $f=0.06 \mathrm{~Hz}$.

- Defects 22.0, 19.0, 15.8, 12.7 and $11.1 \mathrm{~mm}$ in diameter, located in layers 4-5 were detected with the frequency of energy input $f=0.04 \mathrm{~Hz}$.

- Defects 22.0 and $19 \mathrm{~mm}$ in diameter, located in layers 5-6 were detected with the frequency of energy input $f=0.05 \mathrm{~Hz}$.

- The input frequency range $(f=0.05-0.06 \mathrm{~Hz})$ indicated during computer analysis, was confirmed as $f=0.05 \mathrm{~Hz}$ makes it possible to detect defects in a given case (Figure 4).
Defects with the smallest diameters (2.0 and $3.2 \mathrm{~mm}$ ) were not detected in the experiments. Pointing to the calculation parameter IFOV and the applied camera ThermaCam PM290: IFOV $16^{\circ}$ lens, $f / 1.5-1.2 \mathrm{mrad}, \quad I F O V=2 \bullet \operatorname{Arctan} \frac{p}{f^{\prime}} \approx \frac{p}{f^{\prime}}$. It should be noted that the pitch $p$ is in micrometers, whereas the focal length $f^{\prime}$ is in millimeters. Thus the IFOV is in milliradians. $I F O V=p / f^{\prime}, p=3000 \mathrm{~mm} \cdot 1.2 \mathrm{mrad}, p=$ $3600 \mu \mathrm{m}=3.6 \mathrm{~mm}$.

\section{SUMMARY}

Computer modeling of the structure of a composite material with inserted defects made it possible to significantly narrow down the focus of tests, the aim of which was to evaluate the quality of a composite material. 
The results of preliminary tests confirmed that subsurface defects differing in thermal properties from the base material (the composite material) can be detected. The minimum diameter of detected defects for layers 2-3 and 3-4 was $8 \mathrm{~mm}, 11.1 \mathrm{~mm}$ for layers $4-5$, and $19 \mathrm{~mm}$ for layers 5-6. Defects of diameters shorter than $8 \mathrm{~mm}$ were not detected in the experiments. This may have resulted from the process in which the sample was prepared. Defects were cut out in successive layers of the composite material, and then the sample of 16 layers was bound together in high temperature and under suitable pressure. This may have caused smaller defects to reintegrate with the base material. Thus they could not be detected.

\section{REFERENCES}

1. Maldague XPV. Theory and practice of infrared technology for nondestructive testing. New York, NY, USA: Wiley; 2001.

2. Edwin EH, Arnesen T, Hugosson GI. Evaluation of thermal cracker operation by use of infrared camera. In: Snell JR, Wurzbach RN, editors. Thermosense XX. Proceedings of SPIE Volume 3361. Bellingham WA, USA: International Society for Optical Engine (SPIE); 1998. p. 125-36.

3. Dillenz A, Wu D, Breitrück K, Busse G. Lock-in thermography for depth resolved defect characterisation. In: Proceedings of the 15th World Conference on NonDestructive Testing; 2000 [CD-ROM]. Retrieved August 20, 2009, from: http:// www.ndt.net/article/wcndt00/papers/ idn311/idn311.htm
4. Galmiche F, Maldague X. Depth defect retrieval using the wavelet pulse phase thermography. In: Balageas D, Beaudoin J-L, Busse G, Carlomagno GM, editors. Proc. Quantitative Infrared Thermography 5; 2000. Łódź, Poland: Akademickie Centrum Graficzno-Markietingowe Lodart S.A. p. 194-9.

5. Więcek B, Zwolenik S. Zastosowanie termografii $\mathrm{w}$ badaniach nieniszczących metoda fali cieplnej, termografia impulsowa. In: Więcek B, editor. IV Konferencja Krajowa Termografia i Termometria w Podczerwieni, I Szkoła Termograficzna; 2000. Łódź, Poland: CMYK Studio Poligrafii i Reklamy. p. 29-35.

6. Owczarek G, Gralewicz G. Zastosowanie promieniowania podczerwonego do lokalizacji defektów w strukturach materiałów. Warszawa, Poland: CIOP-PIB; 2003.

7. Gralewicz G, Owczarek G, Więcek B. Investigations of single and multilayer structures using lock-in thermographypossible applications. International Journal of Occupational Safety and Ergonomics (JOSE). 2005;11(2):211-5.

8. Gralewicz G, Owczarek G, Więcek B, Tomalczyk K. Optical and ultrasound lockin thermography systems for detection of structural defects. Problemy Eksploatacji. 2006;(63)4:129-36.

9. Wiśniewski S, Wiśniewski TS. Wymiana ciepła. 5th ed. Warszawa, Poland: WNT; 2009.

10. Nowakowski A, editor. Postępy termografii-aplikacje medyczne. Gdańsk, Poland: Wydawnictwo Gdańskie; 2001. 